\title{
Investigation of Typhoon Wind Characteristics on top of Two Adjacent High-rise Buildings
}

\author{
Diefeng Luo ${ }^{1, \text { a }}$, Zhengnong $\mathrm{Li}^{2, \mathrm{~b}}$ \\ 1Shanghai Key Laboratory of Engineering Structure Safety, SRIBS, Shanghai 200032, China \\ ${ }^{2}$ College of civil engineering, Hunan University, Yuelu, Changsha,Hunan,410082, China \\ aluodiefeng@163.com, bzhn88@163.com
}

\begin{abstract}
Keywords: High-rise building; Field measurement; Typhoon; Wind characteristics; Correlation Abstract: This paper studies the wind characteristics measured from two adjacent high-rise buildings. The original results of the wind measurement, including the mean wind speeds and directions, turbulence intensities, gust factors and turbulence integral length scales, are presented. The mean wind speeds and directions measured from the two buildings are very close, thus providing an opportunity to compare the wind characteristics measured on top of them through a statistic method. Therefore, the effects of mean wind speeds and directions on wind characteristics are checked. Valid results of turbulence intensities and gust factors need to meet the requirement that mean wind speed should be larger than $10 \mathrm{~m} / \mathrm{s}$ and mean wind direction should lie between $40^{\circ}$ and $105^{\circ}$, but it is with some hash terms for turbulence integral length scale. The strong wind data of $36 \mathrm{~h}$ is selected to analyze some turbulence characteristics in detail, and wind spectra and correlation of wind speeds between the two buildings are also studied.
\end{abstract}

\section{Introduction}

In a typhoon weather, the harmful vibration of high-rise buildings caused by wind should be given more attention to ensure the safety of structure and the comfort of residents. Knowledge of wind characteristics on top of high-rise buildings is one of the basic researches in structural wind engineering, and the best way to investigate them is to monitor the wind during the passage of typhoon.

In earlier years, several researches of strong wind laid a solid foundation for the study of wind engineering. Through statistics analyses of about 70 spectra of the horizontal component of gustiness in strong winds, the famous wind spectra of Davenport was proposed (Davenport, 1961). Some concepts of the atmospheric boundary layer, such as gradient wind, the power law and roughness length, were proposed to describe different terrain types (Davenport, 1963). And a series of studies, by calculating the gust factor, turbulence intensity and integral scale of wind that recorded from different heights above ground, revealed the effects of heights, terrain roughness and wind speeds on wind characteristics (Harris, 1971; Deaves \& Harris, 1978; Duchene-Marullaz, 1975; Kato et al., 1992).

In recent twenty years, some representative super high-rise buildings in cities of China were monitored to investigate wind characteristics on top of them (Xu \& Zhan, 2001;Fu et al., 2008; Gu et al., 2011). And many studies paid more attention to the wind-induced responses and behaviors of high-rise buildings under the effects of typhoon (Kijewski-Correa et al., 2006; Xu et al. 2003; Li et al., 2008; Guo et al., 2012). With the increase of knowledge of wind characteristics on top of high-rise buildings in urban areas, it verified and improved the current design practices. But, few studies have attempted to investigate the characteristics of winds that simultaneously measured on top of several adjacent high-rise buildings.

In this study, two adjacent high-rise buildings with the approximate height were monitored to measure the wind simultaneously, more than 60 hours of wind records were obtained during typhoon Usagi in 2013. This paper provides an overview of the monitoring program and the results of the wind measurements. Some detailed turbulence characteristics of strong wind data and the correlation of wind speeds between the two buildings are also analyzed. 


\section{Monitor Program setup}

The two high-rise buildings monitored and described in this paper, designated as Building A and Building B, are only about 500m from the sea (Fig. 1(b)). The two high-rise buildings belong to a three-building group. They have similar plan forms and dimensions that are about $60 \mathrm{~m} \times 30 \mathrm{~m}$. Building A and Building B locate in the north of the group with the same orientation and their maximum heights are $102.9 \mathrm{~m}$ and $110.7 \mathrm{~m}$ respectively. The maximum gap between the two buildings is $20.5 \mathrm{~m}$, as is shown in Fig. 2 (b). Another building is designated as Building $\mathrm{C}$ and is $149.8 \mathrm{~m}$ high. When Building $\mathrm{C}$ is in the upwind direction, the wind data on top of Building $\mathrm{A}$ and Building $\mathrm{B}$ might be affected by Building $\mathrm{C}$ and it will be discussed below.

(a)

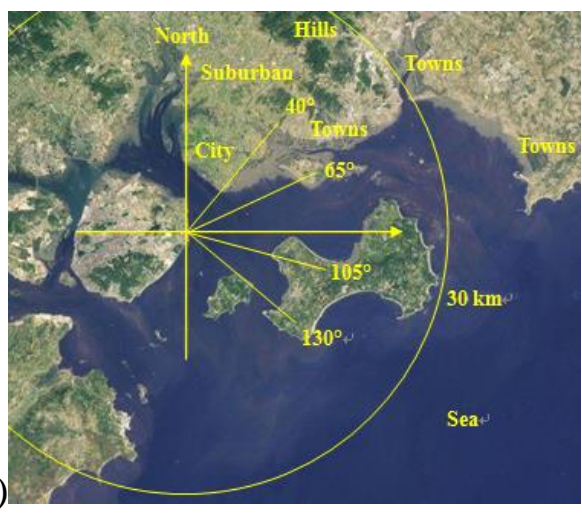

(b)

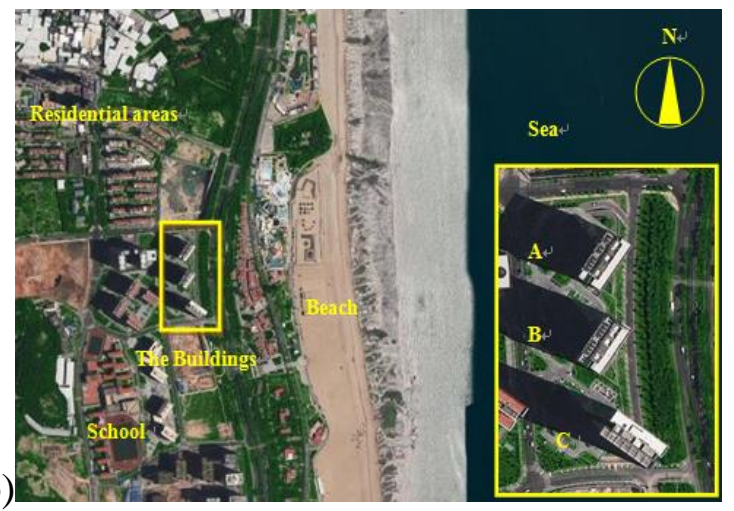

Fig. 1 Satellite views of the measurement site and the monitored buildings: (a) diagram of terrain roughness in different directions; (b) the detailed surroundings.

(a)

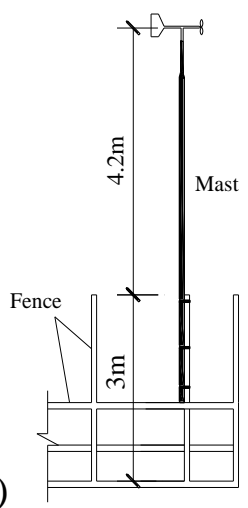

(b)

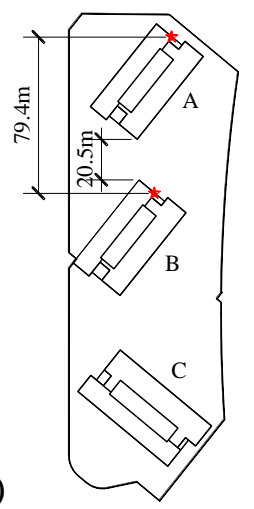

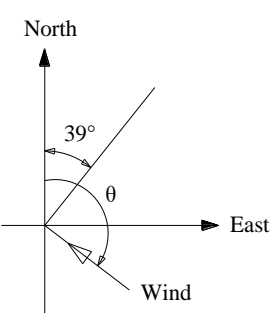

‡ 05103V R.M. Young's propeller anemometers

Fig. 2 Arrangement of R.M. Young's propeller anemometers: (a) a diagram of installation and a picture of the mast; (b) building plans and orientation description of wind.

The terrain around the group buildings is shown in Fig. 1. A coordinate with the measurement site at the origin might be helpful to explain the terrain roughness exposures of each upwind directions interval. Within the distance of $30 \mathrm{~km}$ from the measurement site, the terrain category for respective upwind direction intervals are city, open country and sea (Fig. 1(a)). Detailed surroundings of the building group are shown in Fig. 1(b), between the beach and the building group, there are some low buildings and a coastal road. On the opposite side, there are six lower buildings next to the building group, and an open land is at a distance. Few high-rise buildings that arranged in lines and a music school can be seen in the south, and some residential areas that mostly of low buildings or multi-story buildings are widely distributed in the north. On the whole, the surrounding terrains of the measurement site are flat and open, so the monitored buildings are significantly exposed to wind from some directions.

Strong wind was measured by using two R.M. Young's propeller anemometers that mounted on the masts of each building's roof. The masts are installed in the $3 \mathrm{~m}$ high fences at the east corner of the roof plan, with its height extends $4.2 \mathrm{~m}$ of the fence (Fig.2 (a)). The height difference of the two anemometers, which is $7.8 \mathrm{~m}$, is equal to the height difference of the two buildings and the distance between them is about $80 \mathrm{~m}$. The reference wind direction is $0^{\circ}$ when the wind comes from the north, 
and the angle increases in the clockwise direction. The location of wind anemometers and the description of wind direction can be seen in Fig. 2 (b). The angle between the building's orientation and the north direction is marked out, that is $39^{\circ}$. Obviously the measured wind disturbed by Building A and Building B themselves will be negligible when the northeast wind is blowing.

\section{Typhoon events}

As reported by the Central Meteorological Observatory (CMO) of China, Usagi developed as a tropical storm in the northwest Pacific Ocean on the east of Philippines at 2 a.m., Sept. 17. It rapidly strengthened in the following two days and intensified into a super typhoon with a maximum wind speed reaching about $60 \mathrm{~m} / \mathrm{s}$ near its center during September 19 to 21 . Almost from that time typhoon Usagi started to affect Xiamen for three days continuously. It entered to the sea around the south of Taiwan and weakened into a severe typhoon at 20:00, Sept. 21. It continued to move northwest by west and made landfall in Shanwei of Guangdong city at 20:00, Sept. 22, from where the distance to Xiamen is about $340 \mathrm{~km}$. Typhoon Usagi weakened into a tropical storm over land in the morning of September 23 and dissipated in Guangxi the same day, as shown in Fig. 3.

The wind speeds and wind directions on top of the two high-rise buildings were simultaneously sampled and digitized at $25.6 \mathrm{~Hz}$. The measurement began in the afternoon of September 20 and ended in the morning of September 23, more than $60 \mathrm{~h}$ of wind data were continuously recorded. In that period, the minimum distance from the eye of typhoon to Xiamen is about $270 \mathrm{~km}$. The maximum instantaneous wind speed is $25.9 \mathrm{~m} / \mathrm{s}$ in the records, which was measured on Building A at approximately 01:00, Sept. 22.

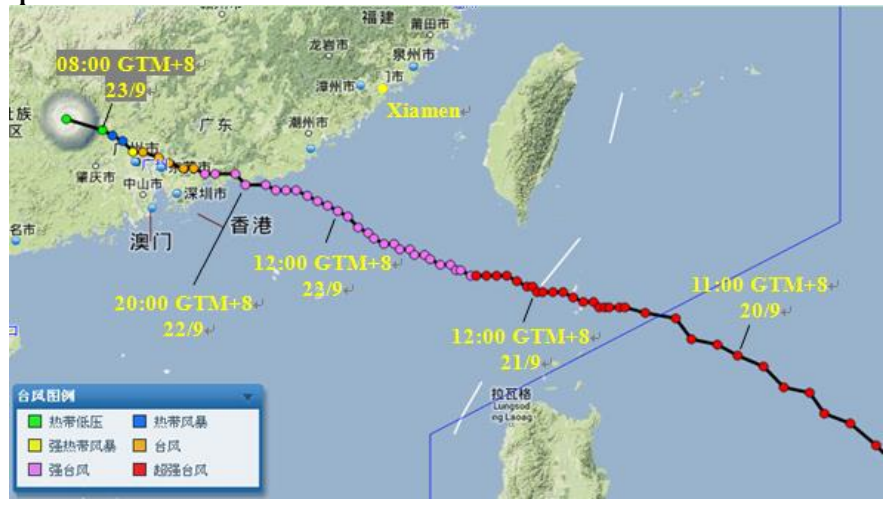

Fig. 3 Track of typhoon Usagi

\section{Results of the wind measurement}

The original records of wind speed and direction time histories were divided into 10-min segments (fully segmented with no overlap) and each individual 10-min segment was then used to evaluate the wind characteristics.

Mean wind speed and direction. The 10-min mean wind speeds and directions $(U$ and $\theta)$ of the recorded data are presented in Fig. 4. Apparently, the mean wind speeds and directions measured by the two anemometers are very close, which provides an opportunity to compare the characteristics of wind on top of the two adjacent buildings. In the whole process of recording, mean wind speed increases linearly first and then decreases with some fluctuations, while mean wind direction remains approximately constant first and then increases linearly with a trough. The maximum mean wind speeds on top of Building A and Building B are $18.9 \mathrm{~m} / \mathrm{s}$ and $16.4 \mathrm{~m} / \mathrm{s}$ respectively. The dominant mean wind directions tend to be between $20^{\circ}$ and $140^{\circ}$ from September 21 to 23 .

The track of typhoon Usagi locates at the south side of Xiamen. Due to the tropical cyclones in the northern hemisphere swirl in a counter clockwise motion, it can be reasonably inferred that the wind direction in Xiamen would change from northeast to southeast during typhoon Usagi. Thus, the change of wind direction in Xiamen corresponds with the track of typhoon. 
(a)
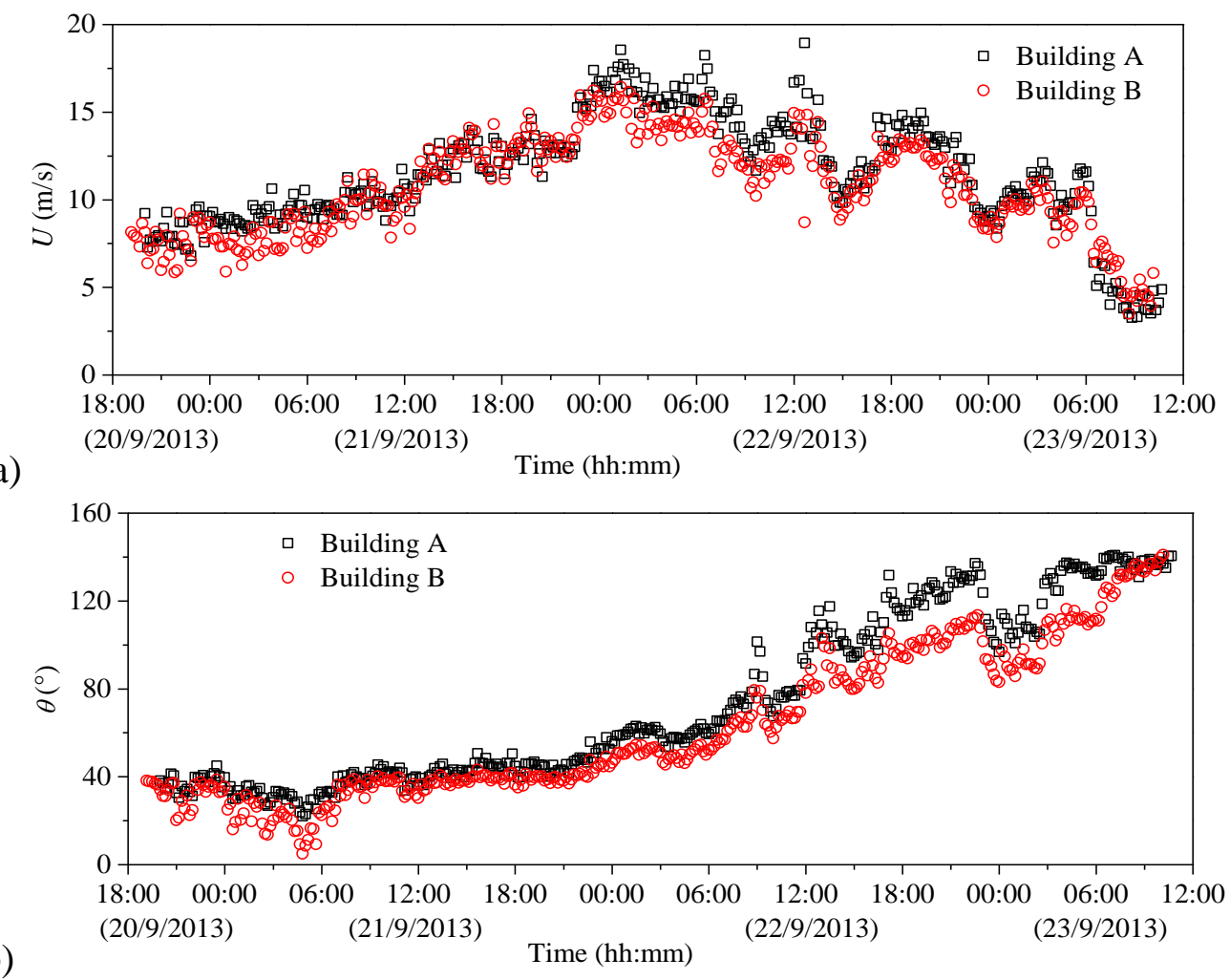

Fig. 4 Comparisons of 10-min mean wind speeds and directions measured from the two buildings, (a) and (b) are respective for 10-min mean wind speeds and directions.

Turbulence intensity. The turbulence intensities in longitudinal and lateral directions $\left(I_{u}\right.$ and $\left.I_{v}\right)$ of the two buildings are compared and presented in Fig. 5. It is shown that the turbulence intensities on top of Building B are much more discrete and with larger values than those of Building A before Sept. 22. And after 6 a.m. of Sept. 23, the turbulence intensities of both the two buildings are discrete and its values increased rapidly, which can be checked in Fig. 4(a) that in that period of time, mean wind speed rapidly reduces to less than $5 \mathrm{~m} / \mathrm{s}$. However, turbulence intensities of the two buildings are very closely in the middle point of that period.

Statistics of the averaged turbulence intensities in each wind speed intervals are conduced to discuss their variations with wind speed, which is shown in Fig. 6. At the top right corner of the figure is a bar plot of number of samples in wind speed intervals (16 intervals with $1 \mathrm{~m} / \mathrm{s}$ as an interval, and the same interval in the following part) and in each interval, turbulence intensities and 10-mean wind speeds are averaged. It is found that the averaged turbulence intensities have a tendency of decreasing with the increasing of the mean wind speed at first and then tending to be a constant. A turning point of the tendency for Building $A$ is when the mean wind speeds are large than $7 \mathrm{~m} / \mathrm{s}$, and for Building B, it is when the mean wind speeds are large than $10 \mathrm{~m} / \mathrm{s}$ according to the study. The difference might be explained by the interference of Building A which is in the upwind position of Building B for some wind directions.

A check on the effect of wind direction on turbulence intensity is presented in Fig. 7, by means of statistic analyses of the averaged turbulence intensities in each wind direction intervals. The number of samples is plotted at the top right corner of the figure (28 intervals with 5 degrees as an interval, and the same in following). It is shown that in some directions $\left(\theta \in\left(40^{\circ}, 105^{\circ}\right)\right)$, the averaged turbulence intensities of the two buildings are close, which is zoom-plotted in Fig. 8. Except that, differences of the two buildings can be significantly distinguished. When $\theta$ is smaller than $40^{\circ}$ or larger than $105^{\circ}$, turbulence intensities on top of Building B are sharply increased, this phenomenon can be deemed unreasonable. Again when $\theta$ is larger than $130^{\circ}$, turbulence intensities on top of Building A can be deemed unreasonable. The city terrain roughness might be one of the reasons that cause high turbulence intensities when $\theta$ is smaller than $40^{\circ}$ (Fig. 1(a)). There is also another reason that contributes to this--the interferences among the building group. 
(a)
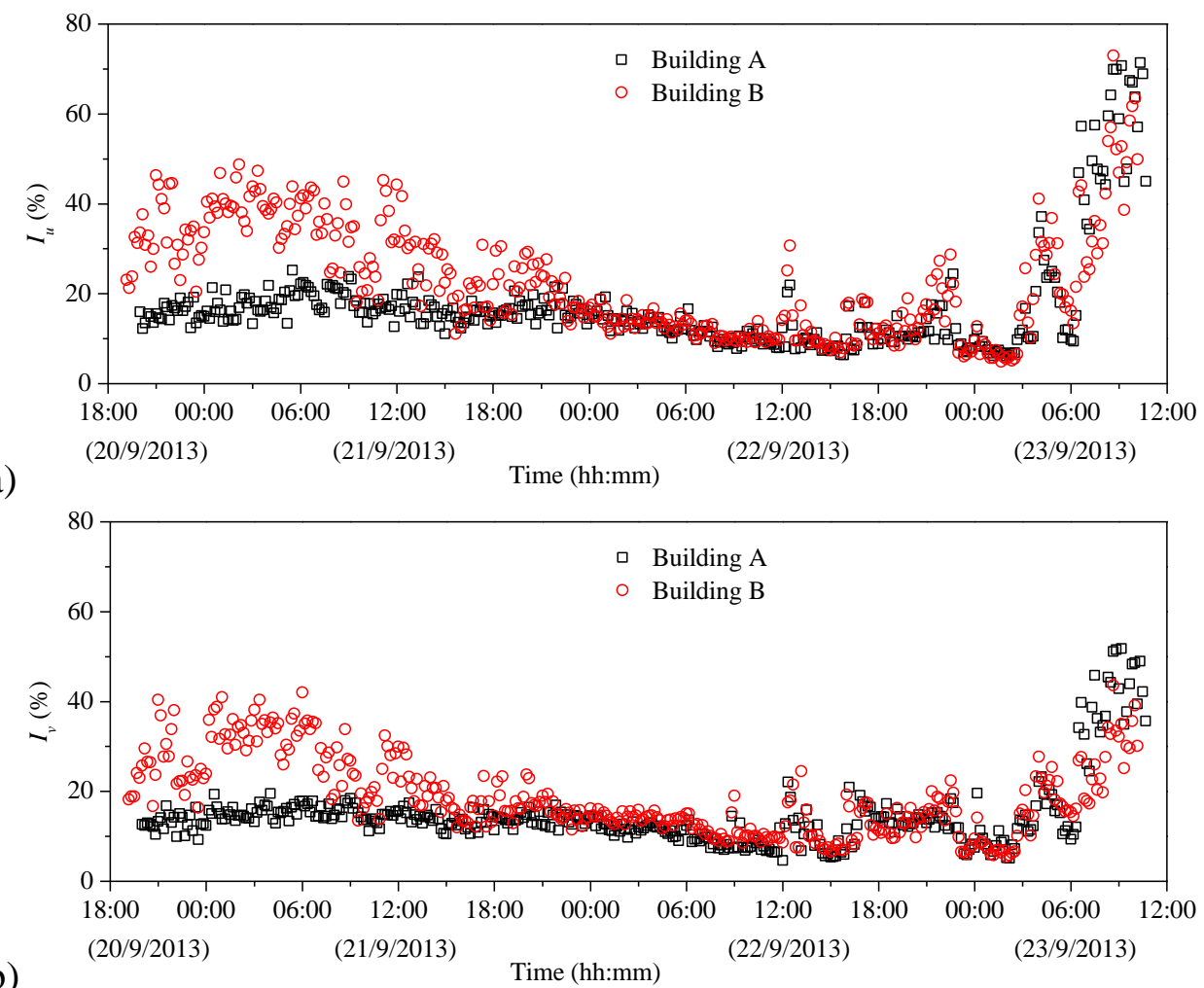

Fig. 5 Comparisons of turbulence intensities measured from the two buildings, (a) and (b) are respectively for the longitudinal and lateral turbulence intensities.

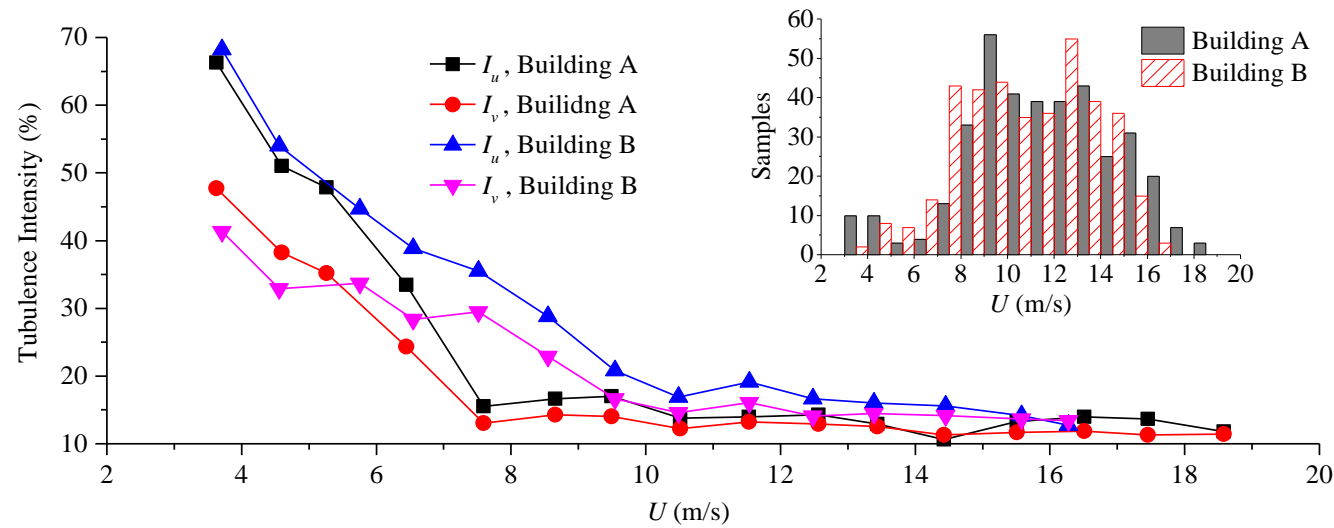

Fig. 6 Averaged turbulence intensities against mean wind speeds through a statistics of wind speed intervals.

Since the two buildings are very close and with similar height, the turbulence intensities should not be very different. However, it can be concluded from Fig. 8 that the wind on top of Building B might be affected by Building $\mathrm{A}$ when $\theta$ is smaller than $40^{\circ}$, and both Building $\mathrm{A}$ and Building $\mathrm{B}$ might be affected by Building $\mathrm{C}$ when $\theta$ is larger than $130^{\circ}$. This states clearly that when $\theta$ is smaller than $40^{\circ}$ or larger than $130^{\circ}$, the interference effects on wind speeds may happen (Fig. 2(b)). Because the upwind building might introduce additional turbulence to the incident wind speeds of the building in the downwind direction. And a billboard in the upwind position of anemometers could be the reason of sharply increased turbulence intensity on top of Building B when $\theta$ changes from $105^{\circ}$ to $130^{\circ}$.

When $\theta$ changes from $40^{\circ}$ to $65^{\circ}$, the turbulence intensities gradually decrease (Fig. 8), and keep on a level around $10 \%$ from $65^{\circ}$ to $105^{\circ}$. This diagram clearly depicts the upwind terrain roughness is changed from open country to sea (Fig. 1(a)). The turbulence intensities varies from $18 \%$ to $7 \%$ at about $110 \mathrm{~m}$, which is comparable with the turbulence intensity predicted in Chinese code (GB50009-2012) when the terrain category changes from Category D (Big City, $I_{u}=0.39 \times$ $\left.(110 / 10)^{-0.3}=19 \%\right)$ to Category A (Sea, $\left.I_{u}=0.12 \times(110 / 10)^{-0.12}=9 \%\right)$. 


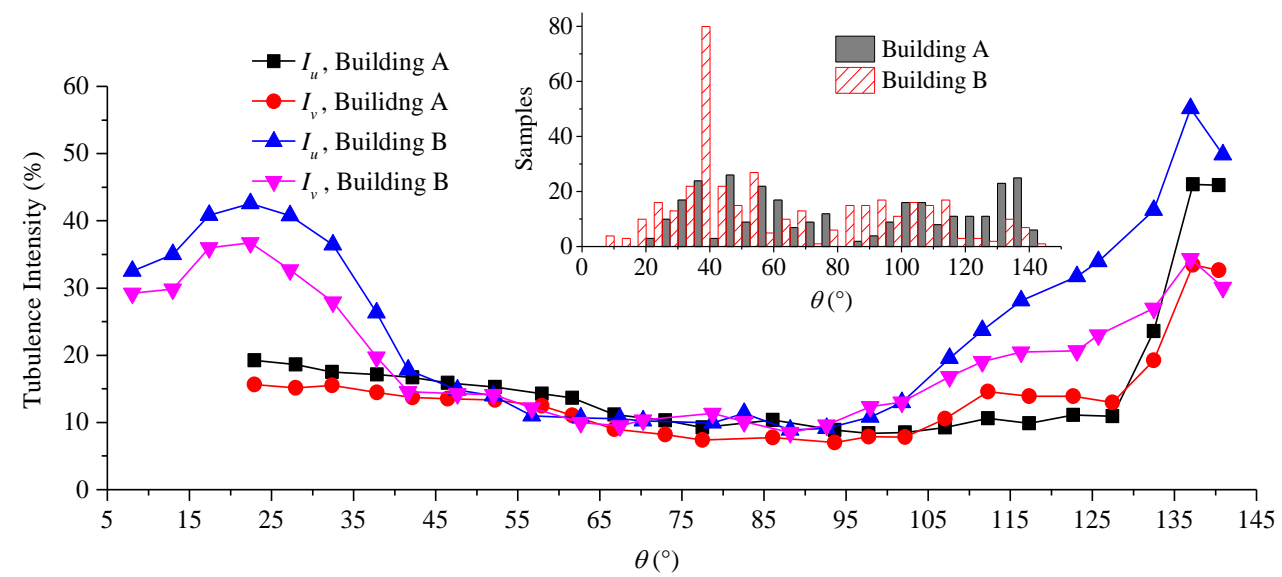

Fig. 7 Averaged turbulence intensities against mean wind directions through a statistics of wind direction intervals.

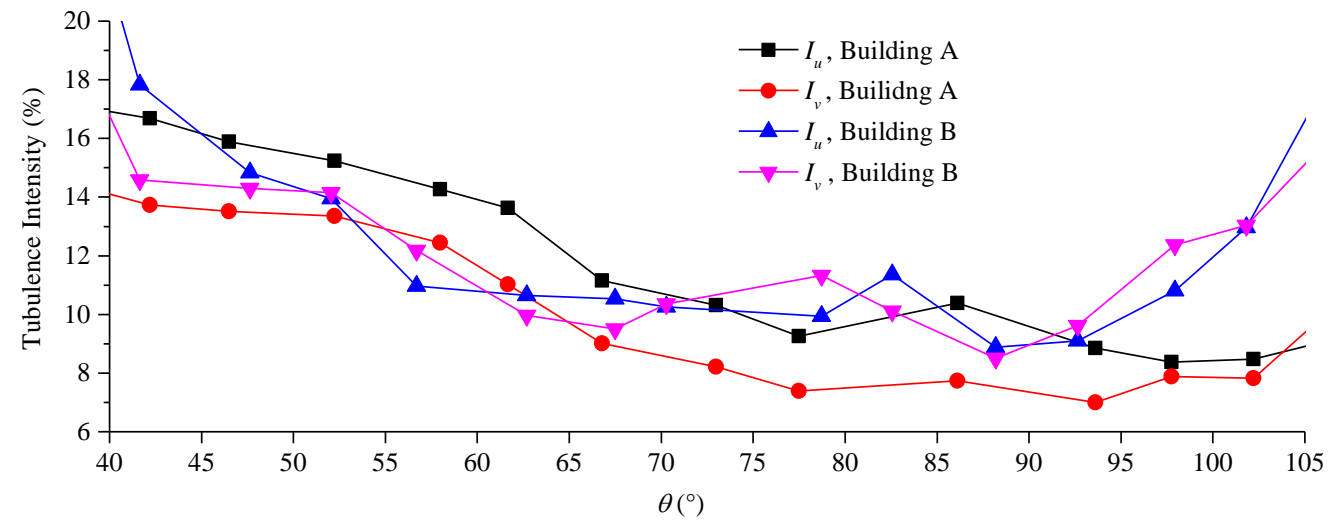

Fig. 8 A zoomed viewport of Fig. 7 when $\theta$ changes from $40^{\circ}$ to $70^{\circ}$

Gust factor. The same statistical method is used to check the effect on gust factors of mean wind speeds and directions, as is shown in Fig. 9 and Fig. 10. A dotted line at the ordinate of 1 distinguishes the longitudinal and lateral gust factors $\left(G_{u}\right.$ and $\left.G_{v}\right)$. The averaged gust factors in Fig. 9 have the similar tendency with turbulence intensities in Fig. 6 that they are decreased with the increase of the mean wind speed. Small differences of the gust factors which trends to be a constant can be observed when the mean wind speed is larger than $10 \mathrm{~m} / \mathrm{s}$. Results presented in Fig. 10 show that in some directions $\left(\theta \in\left(40^{\circ}, 105^{\circ}\right)\right)$, the averaged gust factors of the two buildings are very close; Except that, differences of the two buildings can be easily distinguished, which is similar with the results shown in Fig. 7.

According to the analysis of Fig. 9 and Fig. 10, reasonable results of gust factors should be a statistic of samples within the ranges of mean wind speed larger than $10 \mathrm{~m} / \mathrm{s}$ and mean wind direction between $40^{\circ}$ and $105^{\circ}$. Gust factors that meet these requirements are congregated to analyze statistically. The averaged longitudinal and lateral gust factors on top of Building A (161 samples) are 1.32 and 0.26, while for Building B (146 samples), they are 1.31 and 0.29 respectively.

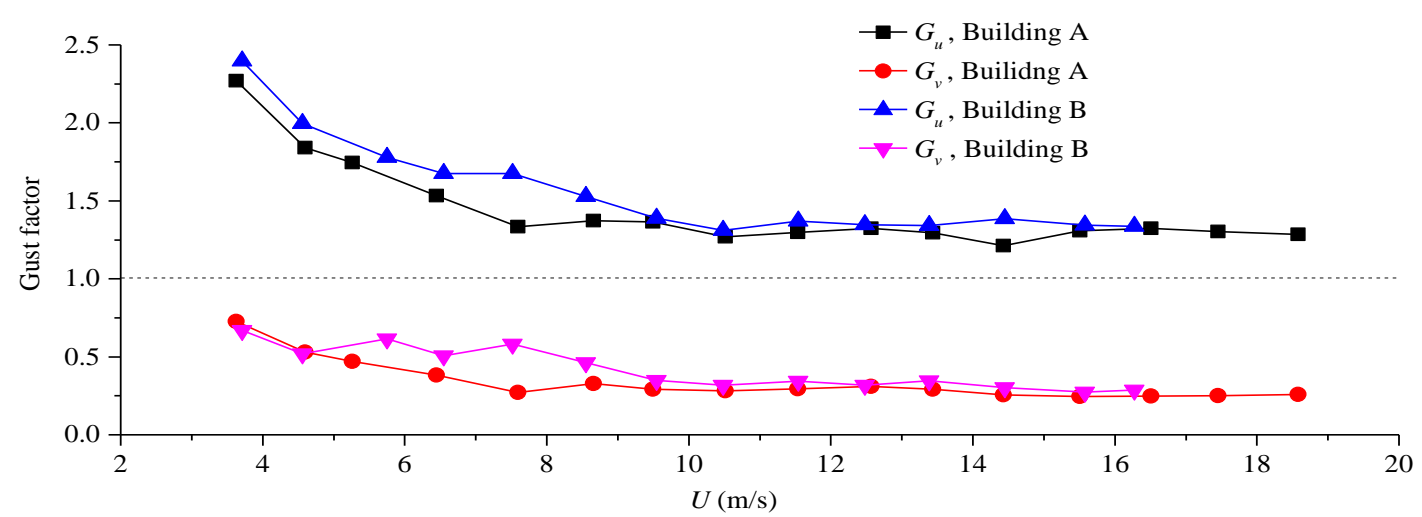

Fig. 9 Averaged gust factors against mean wind speeds through a statistics of wind speed intervals. 


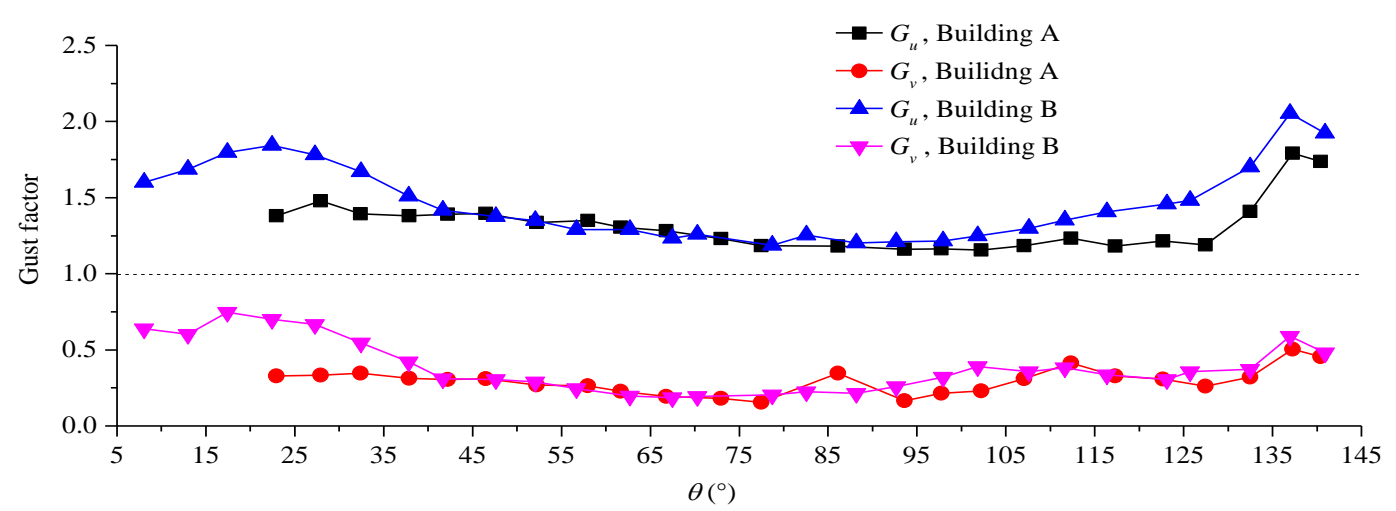

Fig. 10 Averaged gust factors against mean wind directions through a statistics of wind direction intervals.

Turbulence integral length scale. The same statistical method is used to analyze the turbulence integral length scales. When the mean wind speed is less than $8 \mathrm{~m} / \mathrm{s}$, the averaged turbulence integral length scales are very small (Fig.11). As wind speed grows, larger values are maintained and varied from $50 \mathrm{~m}$ to $200 \mathrm{~m}$. Results presented in Fig. 12 show that the averaged turbulence integral length scales increase first and then decrease with the increase of wind direction. Within the range of wind directions $\left(\theta \in\left(70^{\circ}, 105^{\circ}\right)\right)$, the averaged turbulence integral length scales of the two buildings are relatively larger, which is corresponding to the upwind terrain roughness of sea (Fig. 1(a)).

Turbulence integral length scales that meet the requirements of $U>8 \mathrm{~m} / \mathrm{s}$ and $\theta \in\left(70^{\circ}, 105^{\circ}\right)$ are congregated to analyze statistically. The averaged longitudinal and lateral turbulence integral length scale on top of Building A (52 samples) are respectively $232.6 \mathrm{~m}$ and $173.1 \mathrm{~m}$, while for Building B (80 samples), they are $245.2 \mathrm{~m}$ and $189.8 \mathrm{~m}$. There is no relevant provisions in Chinese code could be used to predict turbulence integral length scale, but the values estimated by ASCE-7 and AIJ-2004 are $267.4 \mathrm{~m}\left(\right.$ Sea, $\left.L_{u}=198.12 \times(110 / 10)^{1 / 8}=267.4 \mathrm{~m}\right)$ and $191.5 \mathrm{~m}\left(L_{u}=100 \times(110 / 30)^{0.5}=191.5 \mathrm{~m}\right)$, which is comparable with the measured values.

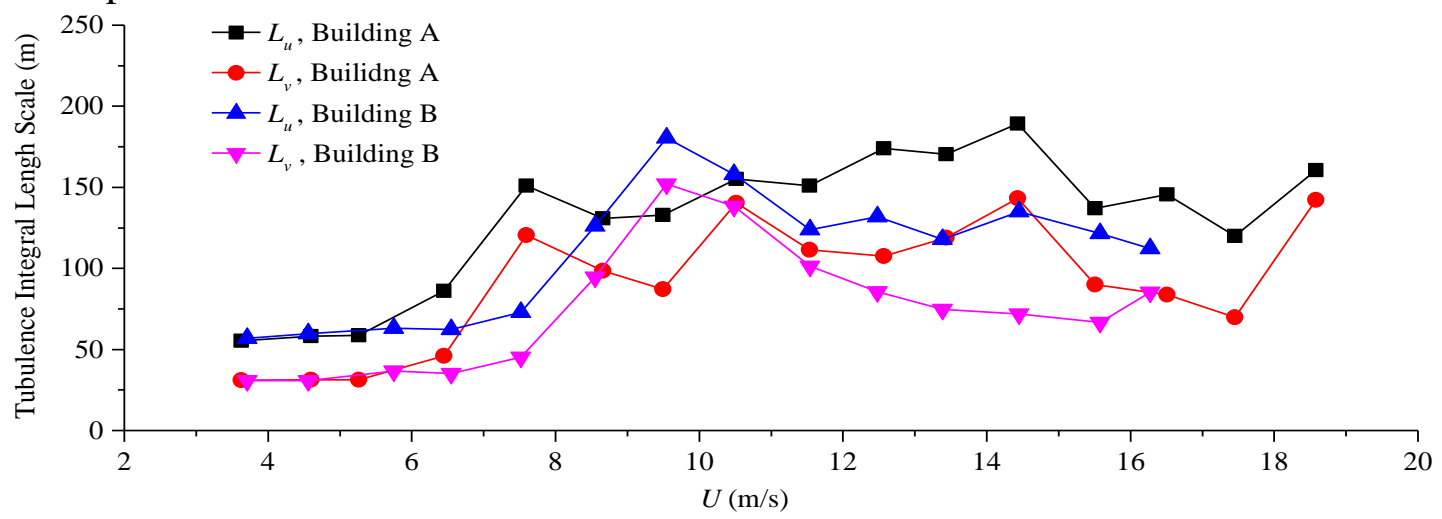

Fig. 11 Averaged turbulence integral length scales against mean wind speeds through a statistics of wind speed intervals.

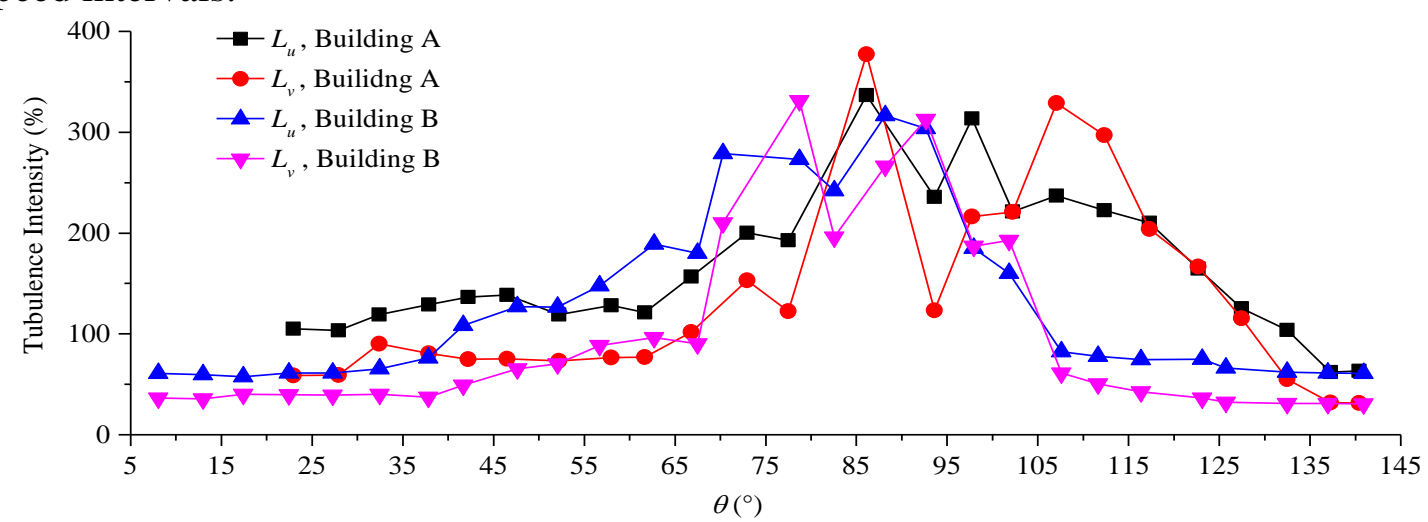

Fig. 12 Averaged turbulence integral length scales against mean wind directions through a statistics of wind direction intervals. 


\section{Detailed analysis of strong wind data}

In this section, continuous strong wind data from the time at 15:00 on September 21 to the time at 03:00 on September 23 is separated to analyze in detail. This set of data with high wind speed may enhance the interpretation of turbulence characteristics.

Relationships of Turbulence intensity and gust factor. Turbulence intensity and gust factor are two important parameters in the determination of fluctuating wind velocity components. According to the research of typhoon wind field by Choi (1983), Ishizaki (1983), a normalized empirical expression was proposed to describe the relationship between gust factor and turbulence intensity in longitudinal direction (Cao et al., 2009), which is:

$$
G_{u}\left(t_{g}\right)=1+k_{1} I_{u}^{k_{2}-1} \ln \left(\frac{T}{t_{g}}\right)
$$

Where $k_{1}$ and $k_{2}$ are two parameters, and $T$ is the time duration of 10 minutes in this study. It was suggested by Choi that $k_{1}=0.62$ and $k_{2}=1.27$, while Ishizaki hold that $k_{1}=0.5$ and $k_{2}=1.0$.

Many field measurements have revealed the linear relationship between the gust factor and the turbulence intensity in longitudinal direction (Gu et al., 2011; Li et al., 2008; Xu et al., 2010), that means $k_{2}=1.0$ has been generally accepted. A comparison of fitting with Eq. (1) for $k_{2}$ as a parameter or a constant of 1 was applied by Gu et al (2011), it turns out that the results calculated by the two methods are almost the same. The linear fitting method is adopted in this paper, for both the relationships of gust factors and turbulence intensities in longitudinal and lateral directions are defined as:

$$
G_{u}\left(t_{g}\right)=1+k_{u} I_{u} \ln \left(\frac{T}{t_{g}}\right), G_{v}\left(t_{g}\right)=k_{v} I_{v} \ln \left(\frac{T}{t_{g}}\right)
$$

The relationship between turbulence intensity and gust factor are fitted with both the expressions of Eq. (1) and Eq. (2), and the fitting parameters are presented in Table 1. It can be seen from the figure that gust factors increase with the increase of turbulence intensities. The shape of the curves fitted with Eq. (1) and Eq. (2) have minor differences. It is hard to compare the fitted parameters of Eq. (1) with the values suggested by Choi and Ishizaki. On the contrary, it is easy to compare the parameters fitted with Eq. (2) because there is only a single parameter to be considered. The fitting parameters of the two buildings agree well with the value suggested by Erich (2005), which is 0.42, especially in the lateral direction. Thus, it shows that Eq. (2) could be more convenient to fit the relationships between the gust factors and the turbulence intensities.

Table 1 Fitted parameters of the two equations

\begin{tabular}{ccccc}
\hline & Building & \multicolumn{2}{c}{ Eq. (1) } & Eq. (2) \\
\hline \multirow{2}{*}{ Longitudinal } & $\mathrm{A}$ & $k_{1}=0.509$ & $k_{2}=2.102$ & $k_{u}=0.416$ \\
& $\mathrm{~B}$ & $k_{l}=0.281$ & $k_{2}=1.795$ & $k_{u}=0.400$ \\
Lateral & $\mathrm{A}$ & & & $k_{v}=0.437$ \\
& $\mathrm{~B}$ & & & $k_{v}=0.420$ \\
\hline
\end{tabular}

Wind spectra. To better estimate the wind spectra of fluctuating wind, continuous strong wind data of $U>10 \mathrm{~m} / \mathrm{s}$ should be selected, and the $36 \mathrm{~h}$ wind data of the two buildings during typhoon Usagi meet the requirement (Fig. 4(a)). The Welch's power spectrum estimation method is adopted here. The longitudinal and lateral wind spectra of the two buildings are plotted in Fig. 13, with the reduced frequency $(n z / u)$ as abscissa and the normalized spectrum as ordinate. The spectrum of von Karman model is also estimated for comparison purpose. It is shown that the measured wind spectra of the two buildings in the longitudinal direction agree well with the von Karman model, but in the lateral direction some differences can be observed. Within the range of the reduced frequency from 0.1 to 2, the measured lateral wind spectra are lower than those from von Karman model, and when the reduced frequency is larger than 2, the measured lateral wind spectra are higher than von Karman 
model. This phenomenon might be caused by the interference of the neighbor building or itself, and this observation needs to be clarified in future study.

(a)
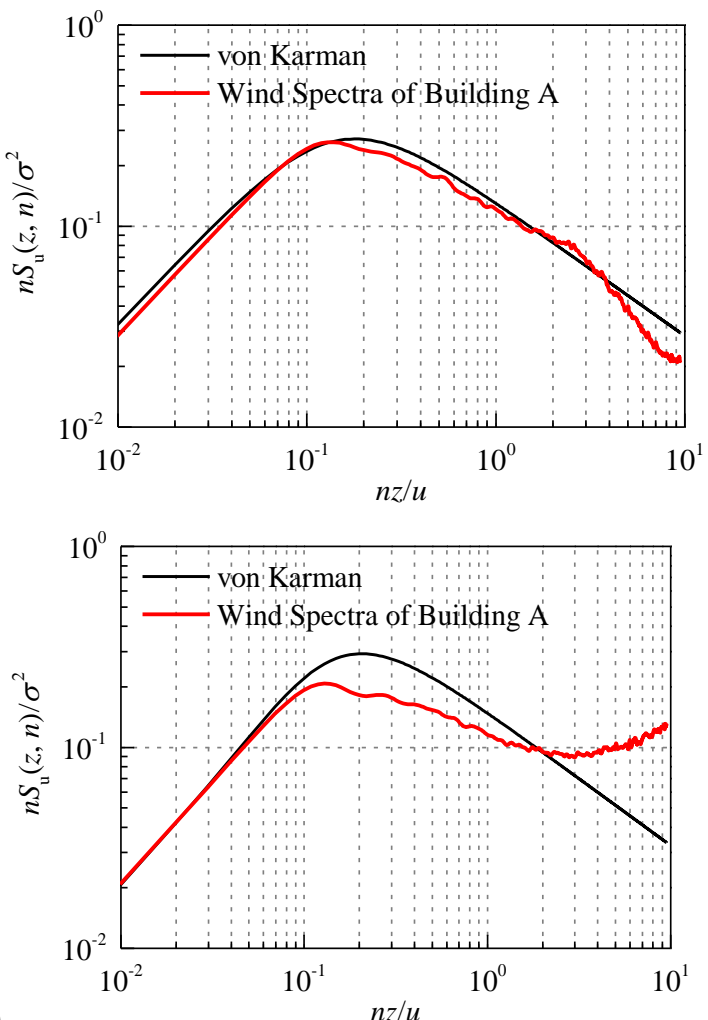
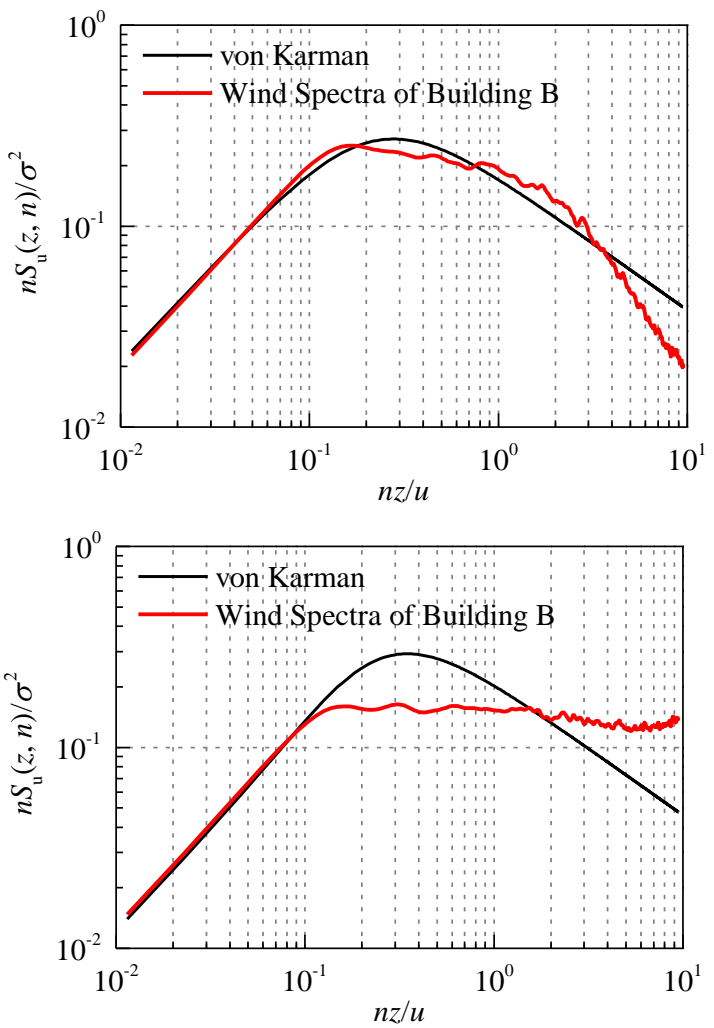

(b)

Fig. 13 Comparison of the wind spectra for the 36 hours and von Karman model, (a) and (b) are wind spectrum of the two buildings respective for the longitudinal and lateral direction.

Spatial correlation coefficients and Coherence functions. The correlation of wind turbulence at two spatial positions can be described in two mathematic methods: spatial correlation coefficient and coherence function. In this paper, two wind anemometer stations are located at $\mathrm{A}$ and $\mathrm{B}$, and the corresponding wind speeds are $\boldsymbol{u}_{\mathrm{A}}=\left(u_{\mathrm{A}}, v_{\mathrm{A}}\right)$ and $\boldsymbol{u}_{\mathrm{B}}=\left(u_{\mathrm{B}}, v_{\mathrm{B}}\right)$. Then the spatial correlation coefficient $\rho_{x_{\mathrm{A}} x_{\mathrm{B}}}$ and coherence function $\mathrm{Coh}_{x_{\mathrm{A}} x_{\mathrm{B}}}(n)$ are respectively defined as follows:

$$
\begin{gathered}
\rho_{x_{\mathrm{A}} x_{\mathrm{B}}}=\frac{E\left[x_{\mathrm{A}} x_{\mathrm{B}}\right]}{\sqrt{E\left[x_{\mathrm{A}} x_{\mathrm{A}}\right] E\left[x_{\mathrm{B}} x_{\mathrm{B}}\right]}} \\
\operatorname{Coh}_{x_{\mathrm{A}} x_{\mathrm{B}}}(n)=\frac{\left|S_{x_{\mathrm{A}} x_{\mathrm{B}}}(n)\right|}{S_{x_{\mathrm{A}}}(n) \cdot S_{x_{\mathrm{B}}}(n)}
\end{gathered}
$$

Where $x$ can be replaced with $u$ and $v$ corresponds to two fluctuating velocity components; $E[\cdot]$ is the calculation symbol of statistic-averaging. In Eq. (6), $S_{u_{\mathrm{A}} u_{\mathrm{B}}}(n)$ means the co-spectral density of $u_{\mathrm{A}}$ and $u_{\mathrm{B}} ; S_{u_{\mathrm{A}}}(n)$ and $S_{u_{\mathrm{B}}}(n)$ mean auto-spectral densities of of $u_{\mathrm{A}}$ and $u_{\mathrm{B}}$ respectively, and so on.

The spatial correlation coefficients of the wind speeds measured from Building A and Building B for each 10min are calculated and shown in Fig. 14. The coefficients of longitudinal fluctuating wind velocities increase with the increase of mean wind speed measured from Building A, and the data is fitted with a linear function (black line) with upper and lower boundaries in the diagram (dashed lines) (Fig. 14(a)). The coefficients in the lateral wind direction hardly changed with the increase of mean wind speed, and the slope of the linear fitting function is very small (Fig. 14(b)). This indicates that wind speed has some significant effect on correlation of the longitudinal fluctuating wind velocity, and the larger the wind speed, the higher the correlation. Correlation of the lateral fluctuating wind velocities between the two buildings is low (the average value of coefficients is about 0.29), and it is almost independent with wind speed. 
(a)

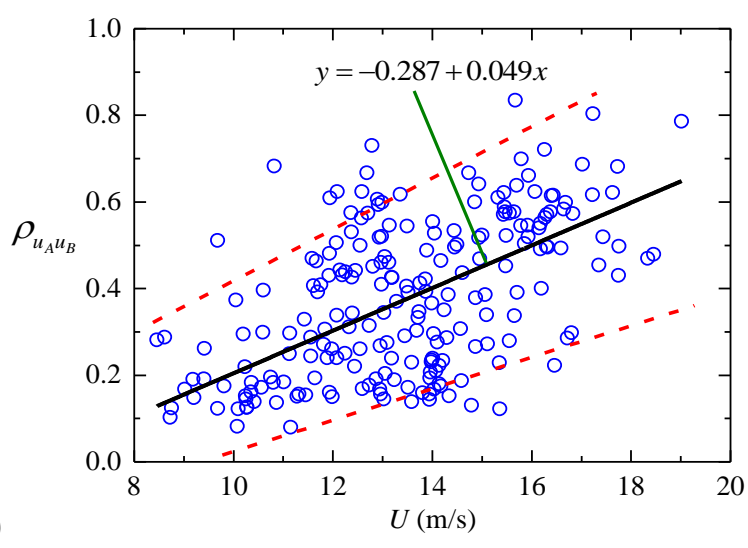

(b)

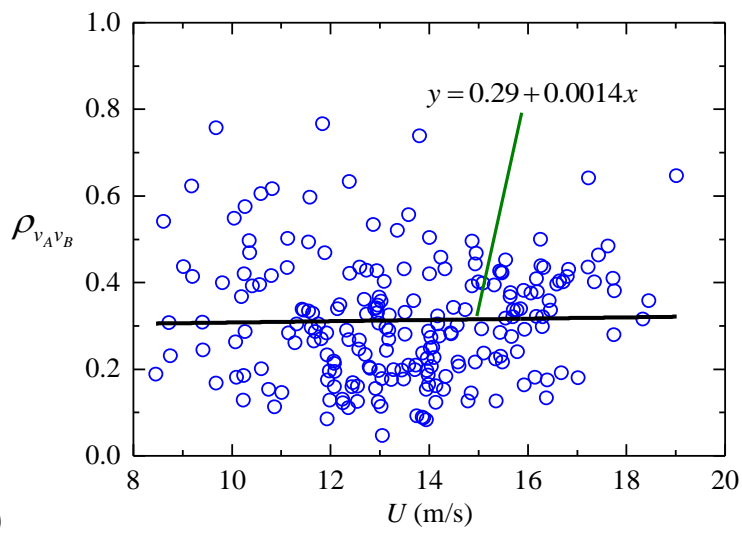

Fig. 14 Spatial correlation coefficients against the mean wind speed measured from Building A: (a) and (b) are the coefficients respectively for the longitudinal and lateral fluctuating wind velocities.

The statistical method that used before is also used to check the effect on spatial correlation coefficients of mean wind direction, as is shown in Fig. 15. At the top right corner of the figure is a bar plot of number of samples in wind direction intervals (19 intervals with $1 \mathrm{~m} / \mathrm{s}$ as an interval). It shows that the averaged coefficients of longitudinal and lateral fluctuating wind velocities are relatively larger respectively for northeast wind $\left(\theta \in\left(40^{\circ}, 60^{\circ}\right)\right)$ and southeast wind $\left(\theta \in\left(90^{\circ}, 110^{\circ}\right)\right)$. This may conclude that when the wind comes from the rougher terrain, correlations of longitudinal fluctuating wind velocities on top of the two buildings are generally higher, and when wind comes from the open terrain, the correlations become lower. However, the upwind terrain roughness has no significant effect on correlations of lateral fluctuating wind velocities.

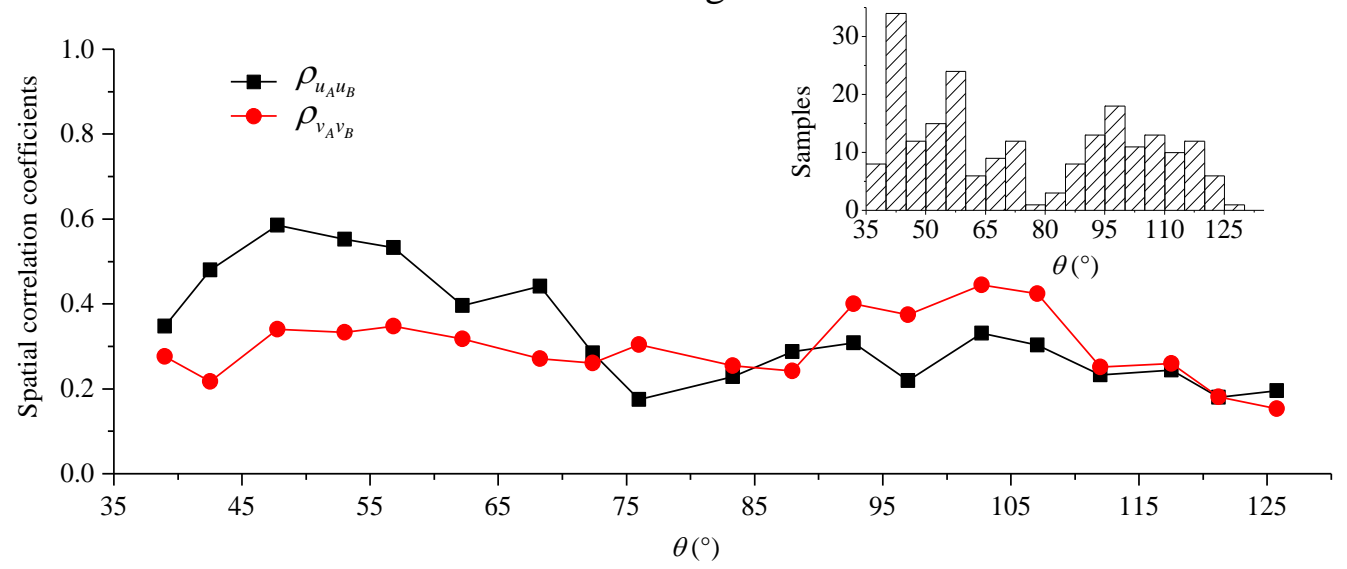

Fig. 15 Averaged spatial correlation coefficients against mean wind directions through a statistics of wind direction intervals.
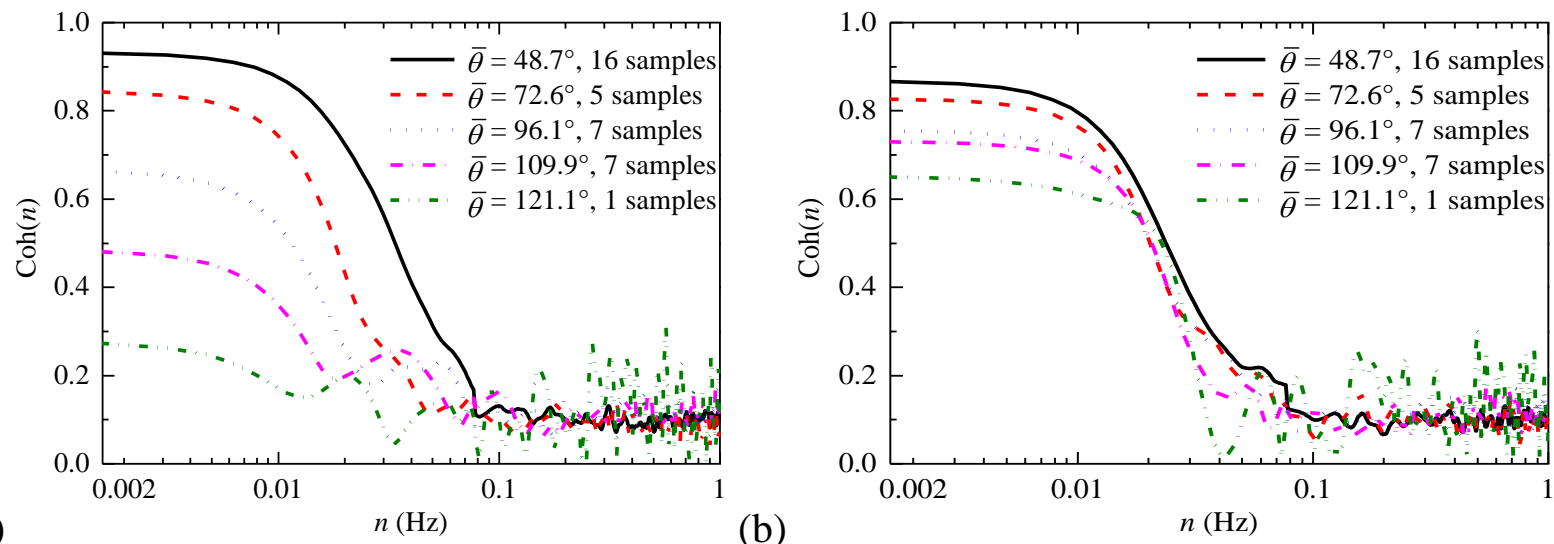

(a)

(b)

Fig. 16 Coherence functions within different wind direction intervals: (a) and (b) are the functions respectively for the longitudinal and lateral fluctuating wind velocities. 
Coherence functions of the fluctuating wind velocities are calculated by hourly samples belong to wind direction intervals of $20^{\circ}$. The hourly wind direction averaged from the two buildings is used to decide the intervals. Coherence functions within different wind direction intervals are shown in Fig. 16 , and directions of each interval are averaged. It can be seen that coherence functions varied with wind directions in the low frequency domain, while it tends to be a constant of 0.1 in the high frequency domain. When the frequency is less than 0.02 , coherence functions of longitudinal fluctuating wind velocities decrease rapidly with the increase of wind direction, and it is more slowly for the lateral fluctuating wind velocities. This may conclude that upwind exposure of terrain roughness and incident wind direction also affect the coherence function, especially for coherence functions of longitudinal fluctuating wind velocities in low frequency domain.

\section{Concluding remarks}

Winds on top of the two adjacent buildings on the east coast of Xiamen city, China, are measured during typhoon Usagi. Basic results of the wind measurement are presented. Some turbulence characteristics of the selected strong wind data are analyzed in detail, and wind spectra and correlation of wind speeds between the two buildings are also studied.

(1) The mean wind speeds and directions measured from the two buildings are very close, which provides an opportunity to compare the wind characteristics. The maximum mean wind speeds approach approximately $20 \mathrm{~m} / \mathrm{s}$, with its directions dominated by a range of $20^{\circ}$ to $140^{\circ}$. And the changes of wind direction are correspond with the track of typhoon.

(2) The reasonable results of turbulence intensities and gust factors should be a statistic of samples within the ranges of mean wind speed larger than $10 \mathrm{~m} / \mathrm{s}$ and mean wind direction between $40^{\circ}$ and $105^{\circ}$. When $\theta$ is less than $40^{\circ}$ or larger than $105^{\circ}$, the main reason caused unreasonable results is the interference effects among buildings. The reasonable results of turbulence intensities vary from $18 \%$ to $7 \%$ at about $110 \mathrm{~m}$, which is comparable with the turbulence intensity predicted in Chinese code when the terrain category changes from Category D to A. The reasonable results of gust factors on top of Building $\mathrm{A}$ for the longitudinal and lateral direction are respectively 1.32 and 0.26 , while for Building B, they are 1.31 and 0.29. The longitudinal turbulence integral length scales of the two buildings with some hash terms are $232.6 \mathrm{~m}$ and $245.2 \mathrm{~m}$ respectively, which is also comparable with the predicted values of ASCE-7 and AIJ-2004.

(3) Relationships between gust factors and turbulence intensities are studied, which shows that gust factors increase with the increase of turbulence intensities. Two methods are used to fit the relationships and little difference is observed. The parameters of the linear fitting method are more simple and easier to compare with other results.

(4) Wind spectra of the two buildings are estimated and compared with the von Karman model. It is shown that wind spectra in the longitudinal direction agree well with the von Karman model, but in the lateral direction, some differences can be observed.

(5) Spatial correlation coefficients and coherence functions between the wind velocities of the two buildings are checked. It indicates that wind speed and terrain roughness could significantly affect the spatial correlation coefficients and the coherence functions of the longitudinal fluctuating wind velocities. The spatial correlation coefficients of the longitudinal fluctuating wind velocities are increased linearly by mean wind speed, and higher coefficients are correspond to rougher terrain. The upwind exposure of terrain roughness and incident wind direction also affect the coherence function, especially for coherence functions of longitudinal fluctuating wind velocities in low frequency domain.

\section{Acknowledgements}

The work described in this paper was fully supported by two grants from the National Natural of Science Foundation of China (Project nos. 91215302 and 51178180). The financial support is gratefully acknowledged. 


\section{References}

[1] Davenport, A. G. (1961), The spectrum of horizontal gustiness near the ground in high winds. Q.J.R. Meteorol. Soc., 87: 194-211.

[2] Davenport, A. G. (1963), The relationship of wind structure to wind loading. Proc. Symposium N.16 on Wind Effects on Building and Structures, National Physical Laboratory, 26-28 June 1963, Teddington, England, 54-102.

[3] Harris, R.I. (1971), The nature of the wind, the modern design of wind sensitive structures. Proceedings of the CIRIA. Paper 3. London. pp. 29-56.

[4] Deaves, D. M., Harris, R.I. (1978), A mathematical mode of the structure of strong winds. CIRIA. Report No 76.

[5] Duchene-Marullaz, P. (1975). Full scale measurement of atmospheric turbulence in suburban area. In Fourth international conference on wind effects on buildings and structures, Heathrow.

[6] Kato, N., Ohkuma, T., Kim, J. R., Marukawa, H., \& Niihori, Y. (1992). Full scale measurements of wind velocity in two urban areas using an ultrasonic anemometer. Journal of Wind Engineering and Industrial Aerodynamics,41(1), 67-78.

[7] Xu, Y. L., \& Zhan, S. (2001). Field measurements of Di Wang tower during typhoon York. Journal of Wind Engineering and Industrial Aerodynamics, 89(1), 73-93.

[8] Fu, J. Y., Li, Q. S., Wu, J. R., Xiao, Y. Q., \& Song, L. L. (2008). Field measurements of boundary layer wind characteristics and wind-induced responses of super-tall buildings. Journal of Wind Engineering and Industrial Aerodynamics, 96(8), 1332-1358.

[9] Gu, M., Kuang, J., Wei X., Xiong, L. J. \& Quan, Y. (2011). Field meansurement of strong wind speed of normal climate on top of Shanghai World Financial Center. Journal of Tongji University (Natural science), 39(11): 1592-1592. (in Chinese)

[10] Kijewski-Correa, T., Kilpatrick, J., Kareem, A., et al. (2006). Validating Wind-Induced Response of Tall Buildings: Synopsis of the Chicago Full-Scale Monitoring Program. J. Struct. Eng., 132(10), 1509-1523.

[11]Xu, Y.L., Chen, S.W., Zhang, R.C., 2003. Modal identification of Di Wang Building under Typhoon York using the Hilbert-Huang Transform Method. Structural Design of Tall and Special Buildings 12, 21-47.

[12]Li, Q.S., Xiao, Y.Q., Wu, J.R., Fu, J.Y., Li, Z.N., 2008. Typhoon effects on super-tall buildings. Journal of Sound and Vibration 313,581-602.

[13] Guo, Y.L., Kareem, A., Ni, Y.Q., Liao, W.Y., 2012. Performance evaluation of Canton Tower under winds based on full-scale data. J. Wind Eng. Ind. Aerodyn. 104-106, 116-128.

[14]Choi, E. C. C. (1983). Gradient height and velocity profile during typhoons.Journal of Wind Engineering and Industrial Aerodynamics,13(1), 31-41.

[15] Ishizaki, H. (1983). Wind profiles, turbulence intensities and gust factors for design in typhoon-prone regions. Journal of Wind Engineering and Industrial Aerodynamics, 13(1), 55-66.

[16]Cao, S., Tamura, Y., Kikuchi, N., Saito, M., Nakayama, I., \& Matsuzaki, Y. (2009). Wind characteristics of a strong typhoon. Journal of wind engineering and industrial aerodynamics, 97(1), 11-21.

[17] Xu, A., Fu, J. Y., Zhao, R. H., \& Wu, J. R. (2010). Field measurements of typhoon according to civil engineering research. ACTA AERODYNAMICA SINICA, 28(1): 23-31. (in Chinese)

[18]Erich, H., \& Renouard, H. V. (2005). Wind Turbines Fundamentals, Technologies, Application. Economics, 2. 